\title{
Impact of Therapy with Selective Serotonine-Reuptake Inhibitors on the Evolution of Subclinical Atherosclerosis in Patients with Depressive Disorder
}

\author{
MARIANA TUDORAN, CATALINA GIURGI-ONCU*, BOGDAN ANDOR*, AHMED ABU AWWAD, GHEORGHE NICUSOR POP, \\ DELIA BERCEANU-VADUVA, CRISTINA TUDORAN \\ University of Medicine and Pharmacy Victor Babes, 2 Eftimie Murgu Sq., 300041, Timisoara, Romania
}

\begin{abstract}
The aim of this study is to highlight the impact of therapy with Sertraline on the AS alterations, in a group of 128 patients with MDD, but without significant CVD or risk factors for atherosclerosis. A secondary goal was to analyze whether there are statistically significant correlations between AS and the intensity of the current depressive episode, as assessed by using the Montgomery-Asberg Depression Rating Scale (MADRS), while also taking into account the duration of MDD.
\end{abstract}

Key words: selective serotonine, reuptake inhibitors, atherosclerosis, depressive disorder

Major depressive disorder (MDD) and cardiovascular diseases (CVD) represent significant public health challenges. There are multiple connections between the two pathologies [1,2]. In subjects without CVD, MDD is associated with a high risk of developing atherosclerosis and heart failure and in patients with coronary artery disease (CAD), arrhythmias or heart failure, it represents a negative prognosis factor [3]. The relation between MDD and CVD is complex and multifactorial, as both pathologies share common sociodemographic, psychosocial, behavioral and biological pathways [4,5]. There are several pathophysiological pathways shared by the two illnesses. One of these is represented by the dysregulation of the hypothalamic-pituitary-adrenal axis, resulting in an increased /prolonged release of cortisol and norepinephrine [6]. Together with a sympathoadrenal hyperactivity and increased vasoconstrictive tone [6], this may induce systemic hypertension and left ventricular hypertrophy (LVH). The imbalance of the autonomic nervous system, represents another mechanism. Inflammation constitutes one of the most important causative factors, owing to its association with increased levels of inflammatory markers, such as C-reactive protein (CRP), interleukin $1 \beta$ and 6 , tumor necrosis factor $\alpha$, impacting on several neurotransmitter systems in the brain, including the serotonin, dopamine and glutamate pathways [7-8]. Genetic factors may play an important role in the relationship between MDD and CVD [9].

Endothelial dysfunction (ED) and arterial stiffness (AS) constitute the earliest manifestations of arterial walls alterations, linked to inflammation, oxidative stress and aging, predisposing to the development of atherosclerosis $[10,11]$. AS is associated with increased catecholamine levels and sympathetic activation. The consequence is an enhanced systemic vascular resistance (SVR) with elevated afterload, leading to LVH. The association between MDD, ED or AS was debated in numerous studies, highlighting the connections with the occurrence of atherosclerosis $(10,12)$.

In recent years, important data has emerged, regarding the potential benefit of antidepressant treatment on the evolution of patients with ED. Most of the research on this topic has focused on the beneficial properties of selective serotonine-reuptake inhibitors (SSRI), with an increased interest on Sertraline, which is currently considered to be the safest and most recommended of the class, in the treatment of patients with depressive illness and comorbid CVD. Recent studies suggest that sertraline treatment in people with comorbid MDD and/or CVD resulted in improved endothelial function, reduced progression of atherosclerosis and the 10-year risk of developing atherosclerotic CVD [13].

\section{Experimental part}

Sertraline hydrochloride, $\mathrm{C} 17 \mathrm{H} 17 \mathrm{Cl} 2 \mathrm{~N}$ or $(1 \mathrm{~S}, 4 \mathrm{~S})-4-(3$, 4-dichlorophenyl)-N-methyl-1,2,3,4-tetrahydronaphthalen1-amine, is a SSRI. More specifically, it inhibits the SERT transporter, which is linked to its mechanism of action as an antidepressant. Sertraline downregulates brain norepinephrine and serotonin receptors in animals. In receptor binding studies, sertraline has no significant affinity for adrenergic (alpha, alpha and beta), cholinergic, GABA, dopaminergic, histaminergic, serotonergic (5HT1A, 5-HT1B, 5-HT2) or benzodiazepine binding sites, explaining why it has less sedative, anticholinergic, and cardiovascular effects than tricyclic antidepressant drugs. It also has mild effects as a dopamine transporter inhibitor, but this hasn't been proven to have a clear clinical implication, besides its activating effect [14-16]. It is approved in the US by the FDA for the treatment of MDD and other psychiatric disorders [13]. SSRIs influence cardiovascular functioning through several mechanisms; for example, they inhibit serotonin-mediated and collagenmediated platelet aggregation, reduce inflammatory mediator levels, and improve ED. SSRIs improve cardiac function in $C A D$ and heart failure without adversely affecting electrocardiographic parameters.

Study group: Out of all the patients with depressive symptoms, which had attended the outpatient psychiatric service of our hospital when suffering with a new depressive episode, from J un 2014 -J un 2018, we selected a group of 128 patients (51 men and 77 women), aged less than fifty-five years. They were diagnosed with MDD, buthad no antidepressant treatment at the moment of the inclusion in the study. We excluded all subjects previously diagnosed with CVD, diabetes mellitus, dyslipidemia or with significant risk factors for atherosclerosis (including

\footnotetext{
*email: catagiurgi@gmail.com, Phone: +40722129835; andormed@yahoo.com. Phone: +40722635134
} 
smoking). Considering the intensity of depressive symptoms, we divided all patients into three subgroups: 60); - group I: forty patients with severe MDD (scores 35 to

- group II: forty-seven patients with moderate MDD (scores 20 to 34 ); to 19$)$;

- group III: forty-one patients with mild MDD (scores 7

Psychiatric evaluation: was performed by a Consultant Psychiatrist who evaluated the intensity of current depressive symptoms in all patients that had been referred for an episode of MDD. The diagnosis of MDD was confirmed by using a short diagnostic interview in order to assess the presence of depressed mood or anhedonia (loss of interest or pleasure) for a minimum of 2 weeks, accompanied by significant functional impairment and additional somatic or cognitive symptoms.

We used the MADRS scale, which is a 10-item rating scale that aims to evaluate the severity of depression based on the total score, with higher scores indicating a greater severity of depression (17). It consists of 10 items that showed not only the greatest variation in response to treatment, but also the best correlation with total score change. Each item is rated from 0 to 6 based on severity $(0=$ no abnormality to $6=$ highest symptom intensity). Total scores on the MADRS range from 0 to 60 . Therefore, the following intensities of depressive symptoms were established: $0-6=$ absence of depression; 7 - $19=$ mild depression; 20 - $34=$ moderate depression and $35-60=$ severe depression. Treatment response is typically defined as a $\geq 50 \%$ improvement in total score, whereas remission is typically defined as an endpointtotal score $\leq 10$ or 12 . The MADRS has high interrater reliability and it correlates significantly with scores of other standard scales for depression, such as the HAM-D [18].

Cardiological evaluation: consisted of a rigorous anamnesis and clinical exam including repeated measurements of the right brachial systolic (SBP) and diastolic blood pressure (DBP).

Assessmnent of carotid to femoral pulse wave velocity (PWV) was done by using applanation tonometry (SphygmoCor, Atcor Medical). Pressure waveforms were determined at the right common carotid and right common femoral arteries. PWV was calculated by measuring the time needed for the arterial waveform to travel between two sites along a vascular segment. Measurements took place in a dark, quiet, temperature-controlled room (21$23^{\circ} \mathrm{C}$ ) and at least three determinations were performed for each patient.

Intima media thickness (IMT) was determined with a Siemens echocardiograph, with a linear transducer, at both common carotid arteries, at the beginning of the dilatation of the carotid bulb. On a frozen optimal longitudinal image of the far wall, we traced the leading edges, corresponding to the transition zones between lumen-intima and mediaadventitia, over a length of $1 \mathrm{~cm}$, proximal to the reference point, at its thickest point, not including plaques. For each subject, IMT was calculated as the mean of three determinations. We noted as pathological IMT values over $0.9 \mathrm{~mm}$.

We followed the patients until the improvement of depressive symptoms which occurred generally, in a time frame of 8-15 weeks and repeated the assessment of AS and IMT after 6 months, in order to observe their evolution.

Data analysis was performed using SPSS v.25.0 (Statistical Package for the Social Sciences, Chicago, IL, USA) for Linux Mint 19. Continuous variables were presented as a mean and standard deviation (SD) or median and associated quartiles (Q1-25 percentage quartile, Q3-75 percentage quartile) and categorical data were presented as counts (percentages). The biascorrected and accelerated (BCa) bootstrap interval (1000 bootstrap samples) was used to calculate the $95 \%$ confidence interval. We performed descriptive and inferential statistics analysis to summarize the characteristics of the study population. The results of the Shapiro-Wilk normality test showed a non-Gaussian distribution, which is why we continued to use nonparametric tests. To evaluate the incidence of AS and IMT in groups, we applied the chi-squared test $\left(\chi^{2}\right)$. In order to highlight the relationship between parameters characterising AS, IMT, LVH and DD and severity of depression we performed the Spearman's rank-order correlation. For comparing the three groups (I, II, III) we used the Kruskal-Wallis $\mathrm{H}$ test followed by a post-hoc analysis with Mann-Whitney $U$ test with Bonferroni correction applied. A p value of less than 0.05 was considered to indicate a statistical significance.

The Ethics Committee of our hospital approved this study and all patients signed an informed consent.

\section{Results and discussions}

This study was conducted on 128 patients, 51 men and 77 women, with ages between 37 and 55 years, mean age $48.49(+5.68)$, who were being initially addressed for a depressive episode. Our patients were divided into three subgroups, according to the severity of their current depressive symptoms, as assessed by the MADRS scale. All patients were not yet treated for the current episode at the moment of inclusion in the study. None of these patients had a past diagnosis of CVD, diabetes mellitus or other significant risk factors for atherosclerosis. Of all the patients, 105 (82.05\%) were overweight, but not obese, and none of their LDL-cholesterol levels were over 140 $\mathrm{mg} / \mathrm{dL}$. Clinical characteristics and laboratory data of all patients are presented in table 1.

In all three groups of patients we noted an increased incidence of altered AS, as expressed by elevated levels of PWV, of over $9 \mathrm{~m} / \mathrm{s}$, significantly higher in patients with severe and moderate MDD ( $p \leq 0.001)$. The incidence of elevated PWV in the whole study group was of $64.84 \%$; however, this was higher in patients with severe or moderate forms of $\operatorname{MDD}(72.5 \%)$, when compared to those with milder forms (46.34\%). Moreover, if we consider values of over $7 \mathrm{~m} / \mathrm{s}$ (the upper limit of the normal range for this age category) as abnormal, all patients with severe depression showed evidence of this abnormality. In all three groups of patients, PWV was strongly statistically correlated with the severity and of depression, see figure 1 , but the correlation with the duration of MDD was the strongest $(r=0.824, p \leq 0.001)$. Another marker of subclinical atherosclerosis, that we evidenced in our patients, was the increased IMT, of over $0.9 \mathrm{~mm}$, with an incidence of $61.71 \%$ in the whole group, but with an even higher incidence, of 70\%, in patients with severe depression $(p \leq 0.001)$. Its values were also strongly correlated with the intensity of depressive symptoms, (fig. 1).

The association between MDD and precocious atherosclerosis was debated in several studies. Smith and Singer argued over the role of AS in the bidirectional relationship between depression and CV morbidity in patients with MDD [3]. In the Maastricht study, Onete et al (12) evaluated MDD by using the Mini-International Neuropsychiatric Interview (MINI) and the Patient Health Questionnaire-9 (PHQ-9) in association with AS by determining PWV in a cohort of 2757 participants, and 
Table 1

RESULTS OF CLINICAL AND LABORATORY DETERMINATIONS IN PATIENT GROUPS

\begin{tabular}{|c|c|c|c|c|c|c|}
\hline \multirow{2}{*}{$\begin{array}{l}\text { Results of clinical and } \\
\text { laboratory data, AS and } \\
\text { IMT }\end{array}$} & \multirow{2}{*}{$\begin{array}{c}\text { Group I: } \\
\text { Severe MDD } \\
40 \text { patients } \\
\end{array}$} & \multirow{2}{*}{$\begin{array}{c}\text { Group II: } \\
\text { Moderate MDD } \\
47 \text { patients } \\
\end{array}$} & \multirow{2}{*}{$\begin{array}{l}\text { Group III: } \\
\text { Mild MDD } \\
41 \text { patients } \\
\end{array}$} & \multicolumn{3}{|c|}{$p$ value } \\
\hline & & & & I-II & I-III & II-III \\
\hline $\begin{array}{l}\text { Mean age (years) } \\
\text { BMI }\left(\mathrm{kg} / \mathrm{m}^{2}\right)\end{array}$ & $\begin{array}{c}49.3( \pm 5.18) \\
28(24,9-29.07)\end{array}$ & $\begin{array}{c}48.74( \pm 5.55) \\
26.7(25.8-27.9)\end{array}$ & $\begin{array}{c}47,41( \pm 6.22) \\
26.1(25.1-28.05)\end{array}$ & & $\begin{array}{l}\text { NS* } \\
\text { NS* }\end{array}$ & \\
\hline LDL-cholesterol (mg/d1) & $120(117$. & $15-120)$ & $112(109-115)$ & 0.267 & $<0.001$ & $<0.001$ \\
\hline CRP $(\mathrm{mg} / \mathrm{dl})$ & $3.5-5.3)$ & $.1-4.4)$ & & 0.091 & $<0.001$ & $<0.001$ \\
\hline Duration of RD (months) & & & & 1 & 0.001 & 0.003 \\
\hline MAD & $44(3$ & $-32)$ & & $<0.001$ & $<0.001$ & $<0.001$ \\
\hline PWV (m/sec) & $12.05(10.9-13.62)$ & $10.6(8.9-11.3$ & $9(7.85-11)$ & 0.020 & $<0.001$ & 0.035 \\
\hline SBPc (mm & $136.2(123.7-143.2)$ & $127.5(117.5-132.5$ & $120(110-124)$ & 0.001 & $<0.001$ & 0.003 \\
\hline DBPc (mm & $93.8(83.9-1003)$ & $88.7(83.7-93.7)$ & $81(71-82.5)$ & 0.668 & $<0.001$ & $<0.001$ \\
\hline LVMI $\left(\mathrm{g} / \mathrm{m}^{2}\right)$ & $121(99-130.75)$ & $115(98-124)$ & $113(96-117)$ & 0.172 & $<0.001$ & 0.092 \\
\hline IMT (mm) & $1.15(1.05-1.45)$ & $1.1(0.89-1.3)$ & $0.8(0.7-1.2)$ & 0.159 & $<0.001$ & 0.100 \\
\hline
\end{tabular}

Legend: AS - arterial stiffness; IMT - intima-media thickness; BMI - body mass index; LDL - low density lipoproteins; CRP - C reactive protein; MADRS - Montgomery-Asberg depression rating scale; PWV - pulse wave velocity; SBPC central systolic blood pressure; DBPC - central diastolic blood pressure; LVMI - left ventricular mass index; IMT intima-media thickness. *Kruskal-Wallis test; post-hoc U-Mann Whitney test with Bonferroni correction applied.

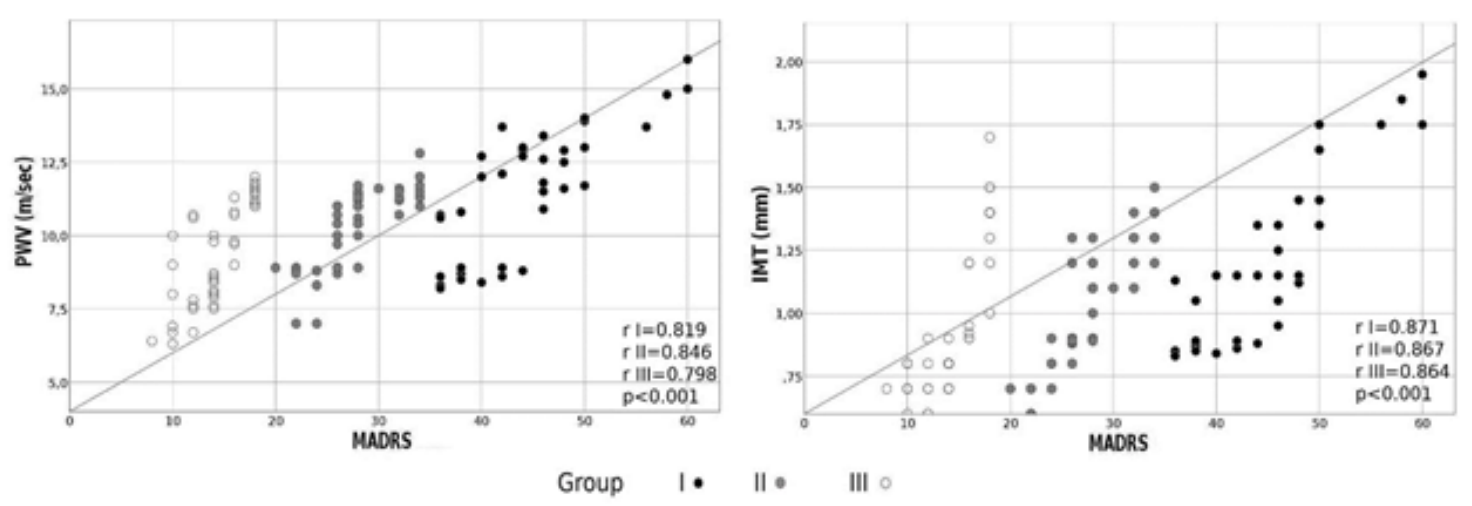

Legend: Major depressive disorder; Group I- Severe MDD; Group II - moderate MDD; Group III - mild MDD; PWV - pulse wave velocity; IMT - intima-media thickness; MADRS - Montgomery-Asberg depression rating scale; Spearman rank order correlation test.

scale

Fig. 1. Correlations between the alteration of PWV and IMT and the intensity of depressive symptoms assessed by MADRS scale

found that MDD and depressive symptoms, as well as AS were higher among middle-aged men, and to a lesser extent, in women. In our study we found no statistically significant differences between gender.

Similar results were reported by Van Sloten in the AGESReykjavik Study Artery Research (10).

Poongothai et al determined the incidence of MDD, AS, but also of IMT, in a cohort of 1505 participants included in the Chennai Urban Rural Epidemiology Study (19), which evidenced increased AS and IMT values in depressed patients. Khandoker etal, analysed the increased incidence of AS, as assessed solely by PWV and by PWV and Fingertip Photo-Plethysmography in smaller groups of depressed patients with suicidal intention, but without comorbid CVD (20). Other results of recent metaanalyses of prospective cohort studies, conducted on subjects that were initially free of CVD, indicate that depression was associated with a $30 \%$ increased risk of future coronary events $[10,12,13,21]$.

After the initial evaluation, our patients started therapy with sertraline, in a dose ranging from 50 to $100 \mathrm{mg} /$ day. Psychiatric evaluation was repeated after 8 weeks of therapy and revealed good response in all patients with mild MDD, but in the other groups, there were subjects who, although improved, did not meet the criteria for responders. These patients were offered a higher dose of sertraline $(150 \mathrm{mg} /$ day) with good response in most cases. At 6 months we registered a remission in all patients with mild MDD, in $81.48 \%$ from group II and in $70 \%$ from group I, with a significant decrease of the MADRS score $(p \leq 0.001)$, (fig. 2).

For this study, we analyzed the evolution of depressive symptoms after 6 months of therapy with sertraline and highlighted a significant improvement of the MADRS score, (fig. 2). Referring to AS alterations, we noticed a significant reduction of $P W V$ values, in all three patient groups $\left(Z_{1}=\right.$ $4.860, Z_{2}=-5.977$ and $Z_{3}=-5.581$, all with $p<0.001$ ), see figure 2. Regarding the morphological signs of subclinical atherosclerosis, reflected by IMT, there was a significant regression, mostly in group I and II ( $p<0.001)$, (fig. 2). No significant difference regarding the evolution of PWV and IMT between genders was determined.

There are few data in the medical literature regarding the evolution of AS alterations in patients with MDD treated with SSRI. In an earlier study, Santangelo et al, presented the reduction of CV risk in older patients treated with SSRI [22]. Hansen et al reported over the beneficial effect of physical effort on the AS reduction [23].

Hantsoo et al discussed over the evolution of endothelial dysfunction in women with MDD and treated with SSRI [24]. On the other hand, in his study, Scuteri et al debated upon differences between the action of different antidepressants, duloxetine determining even the augmentation of PWV in elderly, comparing to escitalopram who had a neutral effect [25-32]. 

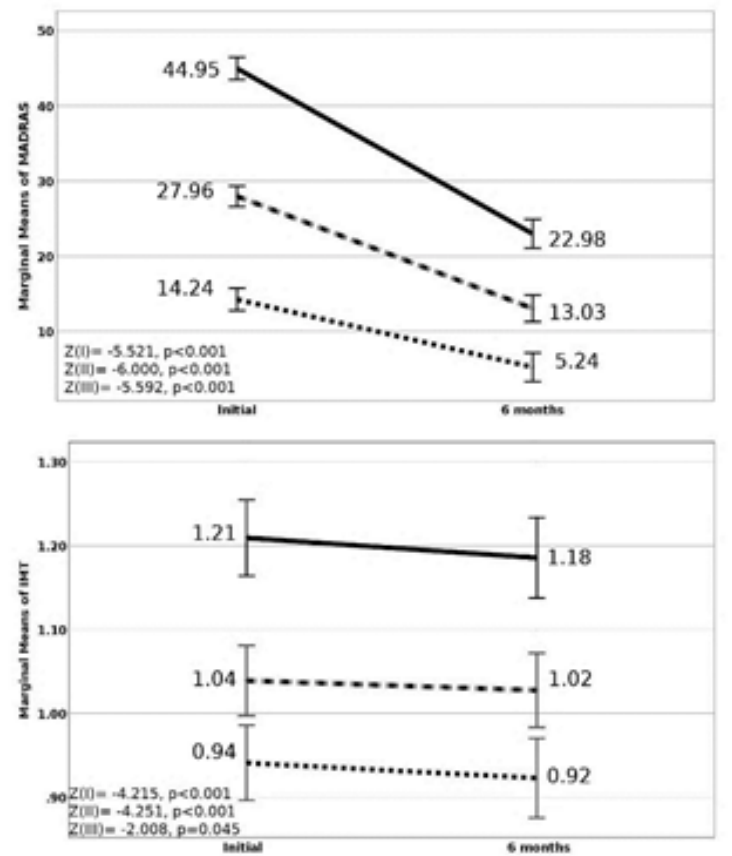

\section{Conclusions}

Subclinical atherosclerosis, expressed by increased PWV and IMT, was a common finding among patients with MDD and was correlated with the severity and duration of depressive symptoms. Therapy with sertraline significantly reduced the intensity of depressive symptoms and AS alterations.

\section{References}

1. PENNINX, B.W.J.H., Neuroscience \& Biobehavioral Reviews, 74, 2017, p. 277

2. HUFFMAN, J.C., CELANO, C.M., BEACH, S.R., MOTIWALA, S.R., JANUZZI, J.L., Cardiovasc Psychiatry Neurol., 2013, p. 1.

3. SMITH, E., SINGER, J., Cardiovascular Diseases and Depression, Treatment and Prevention in Psychocardiology, 2016, p.187.

4. OGILVIE, R.P., EVERSON-ROSE, S.A., LONGSTRETH, W.T. J r, RODRIGUUEZ, C.J ., DIEZ-ROUX, A.V., LUTSEY, P.L., Circ. Heart. Fail., 2016, p. 1.

5. CELANO, C.M., SHAPTER, C., STYRA, R., Psychiatric times, 33, nr. 12, 2016, p. 1.

6. MALPAS S.C., Physiol Rev., 90, 2010, p. 513.

7. MILLER A.H., RAISON C.L., Nat. Rev. Immunol., 16, 2016, p. 22.

8. EFFENDY E., In: IOP Conf. Ser.: Earth Environ. Sci., 125, nr. 1, 2018.

9. COZMA, A., SITAR TAUT, A., ORASAN, O., PROCOPCIUC, L.M., FARCAS, A.D., ADINA STAN, A., NEGREAN, V., SAMPELEAN, D., POP, D., ZDRENGHEA, D., FODOR, A., Rev. Chim. (Bucharest), 69, no. 9, 2018, p. 2351.

10. VAN SLOTEN T., MITCHELL G., SIGURDSSON S., VAN BUCHEM M., JONSSON P, GARCIA M., Artery Research, 8, nr. 4, 2014; p. 141.

11. TUDORAN M., TUDORAN C., Kardiologia Polska, 73, nr. 5, 2015, p. 337.

12. ONETE V., HENRY R.M., SEP S.J.S., KOSTER A., VAN DER KALLEN C.J ., DAGNELIE P.C., J. Psychiatry. Neurosci., 43, nr. 2, 2018.

13. SHERWOOD A., BLUMENTHAL J.A., SMITH P.) ., WATKINS L.L., HOFFMAN B.A., HINDERLITER A.L., Psychosomatic medicine, 78, nr. 5, p. 602.

14. AGEU, L., TALPOS, C., KANALAS, G., CRISAN, S., C.L., POROCH, V., ANGHEL, M., Rev. Chim. (Bucharest), 69, no. 3, 2018, p. 621. 15.MACQUEEN G., BORN L., STEINER M., CNS drug reviews, 1, 2017, p. 1.

16. STAHL M.S., LEE-ZIMMERMAN C., CARTWRIGHT S., MORRISSETTE A.D., Current drug targets, 14, nr. 5, 2013, p. 578.

17. MONTGOMERY S.A., ASBERG M., Br] Psychiatry, 134, 1979, p.382. 18. MAUST D., CRISTANCHO M., RUSHING L.G.S., TIOA C., THASE M.E., Psychiatric rating scales. In: Handbook of Clinical Neurology. ELSERVIER, 2012, p. 227.

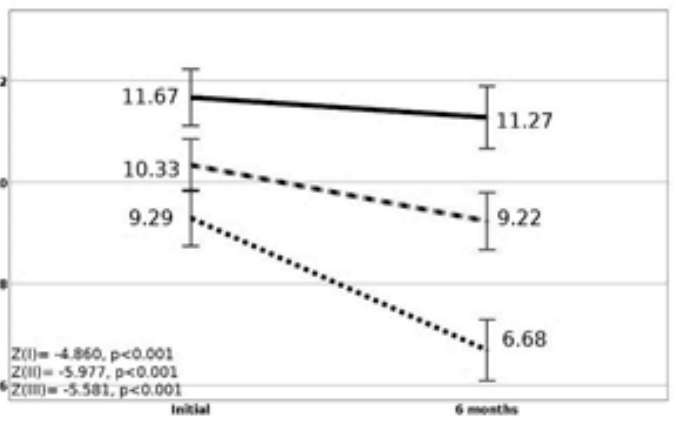

Group: I I $\quad$ II I I III $\because$

egend: MDD - Major depressive disorder;

roup I - severe MDD;

II - moderate MDD

III - mild MDD

- Montgomery-Asberg depression rating scale;

pulse wave velocity;

T - intima-media thickness;

Fig. 2. Evolution of

the intensity of

depression

expressed by

MADRS scale, of

PWV and IMT

19. POONGOTHAI S., PRADEEPA R., INDULEKHA K., SURENDAR J ., MOHAN V., Indian J ourn End Met., 19, nr. 1, 2015, p. 136.

20. KHANDOKER A.H., LUTHRA V., ABOUALLABAN Y., SAHA S., AHMED K.I., MOSTAFA R., Computing in Cardiology, 42, 2015, p. 1061.

21. GEIJ SELAERS, S.L.C., Simone J.S. SEP, S.J .S., SCHRAM, M.T., VAN BOXTEL, M.P.J, VAN SLOTEN, T.T., HENRY, R.M.A., REESINK, K.D., KROON, A.A., KOSTER, A., SCHAPER, N.C., DAGNELIE, P.C., VAN DER KALLEN, C.J .H., BIESSELS, G.J., STEHOUWER, C.D.A., Atherosclerosis, 2016.

22.SANTANGELO A., TESTAI M., BARBAGALLO P., CRISAFULLI C., GRASSO, S.,MANUELE S., MUSCARA G., RIZZOTTO M., TOMARCHIO M., MAUGHERI D., Arch. Gerontol. Geriatr., 48, nr. 3,2009, p. 350

23. HANSSEN H., MINGHETTI A., FAUDE O., SCHMIDT-TRUCKSASS A., ZAHNER L., BECK J., DONATH L., Front Psychiatry, 8, 2017, p. 311.

24.HANTSOO L., CZARKOW SKI K.A., CHILD J., HOWES C., EPPERSON C.N., J Womens Health , 23, nr. 7, 2014, p. 613.

25. SCUTERI A., MODESTINO A., FEDULLO F., ASSISI A.P., GIANNI W., J. Gerontol. A. Biol. Sci. Med. Sci., 68, nr. 6, 2013, p. 719.

26. ABU AWWAD, A., PREJBEANU, R., VERMESAN, D., DELEANU, B., IONITESC, M., FLORESCU, S., VLAD, C.D., DUMITRASCU, V., Dose Effect Of Local Betamethasone Injection In Low Back Pain, Chemistry Magazine Rev. Chim.(Bucharest), 69, no 9, 2018, p. 2382

27. ABU AWWAD A., PREJBEANU, R., VERMESAN, D., BRANEA, I., DELEANU, B., FLORESCU, S., VLAD, V. D., Blood Loss Of Pedicle Subtraction Osteotomy For Sagittal Imbalance Spinal Deformity, Chemistry Magazine, Rev. Chim. (Bucharest), 69, no 12, 2018, p. 3680 , p. 3680

28.TUDORAN, C., TUDORAN,M., PARV, F., POP, G. N., ABU AWWAD, A., VLAD, M., BALA, M., Factors Influencing The Evolution Of Pulmonary Hypertension In Patients With Hyperthyroidism, Chemistry Magazine Rev. Chim. (Bucharest), 70, no 4, 2019, p.1328

29. TUDORAN, M., TUDORAN, C., VLAD, M., BALAS,M., ABU AWWAD,A., POP, G. N., Impact Of Therapy With L-Thyroxine On The Evolution Of Arterial And Aortic Stiffness In Female Patients With Overt And Subclinical Hypothyroidism, Rev.Chim.(Bucharest), 70, no 4, 2019, p. 1372

30. TUDORAN, M.,TUDORAN,C.,CIOCARLIE,T., POP, G.N., BERCEANUVADUVA, M.M., VELIMIROVICI, D.E., ABU AWWAD A., BERCEANUVADUVA, D.M., Aspects of Heart Failure in Patients with Ischiemic Heart Disease after Percutaneous Coronary Revascularization with Polymer-coated Drug-Eluting Stents versus Bare-Metal Stent, Mat.Plast., 56, no 1, 2019, p.37

31. TUDORAN, M., TUDORAN, C., Nigerian J ournal of Clinical Practice, 19, no. 6, 2016, p. 831

32. TUDORAN, C., TUDORAN, M., VLAD, M., BALAS, M., POP, G.N., PARV, F., Anatol J. Cardiol, 20, nr. 3, 2018, p. 174

Manuscript received: 23.10 .2018 